\title{
Corrigendum
}

\section{Burden on Caregivers of Adults with Multiple Chronic Conditions: Intersectionality of Age, Gender, Education level, Employment Status, and Impact on Social Life-CORRIGENDUM}

Sunita Ghosh, Won Yong Choi, Allison Williams, Wendy Duggleby, Jenny Ploeg, Maureen Markle-Reid, and Shelley Peacock

https://doi.org/10.1017/S071498081900045X. Published by Cambridge University Press, 2 September 2019

The funding information was omitted from the original online version of the article by Ghosh et al. (2019) in Canadian Journal of Aging. It is as follows:

This work is part of a program of research (Aging, Community and Health Research Unit) supported by the Canadian Institutes of Health Research Signature Initiative in Community-Based Primary Healthcare (http://www.cihrirsc.gc.ca/e/43626.html) (Funding Reference Number: TTF 128261).

This funding information has been added online and will be added in print.

\section{Reference}

Ghosh, S., Choi, W. Y., Williams, A., Duggleby, W., Ploeg, J., Markle-Reid, M., Peacock, S. Burden on caregivers of adults with multiple chronic conditions: Intersectionality of age, gender, education level, employment status, and impact on social life. Canadian Journal on Aging / La Revue canadienne du vieillissement. https:/ / doi.org/10.1017/S071498081900045X. Published by Cambridge University Press, 2 September 2019. 